\title{
ПРАВОВОЕ ОБЕСПЕЧЕНИЕ НАЦИОНАЛЬНОЙ БЕЗОПАСНОСТИ: ОБЪЕКТ, ПРЕДМЕТ И ЗАДАЧИ
}

\begin{abstract}
Аннотация: Статья посвящена теоретическому обоснованию объекта, предмета и задач правового обеспечения национальной безопасности. Правовое обеспечение национальной безопасности требует четко определить тот объект, отношения в котором подлежат правовому регулированию, предмет этого регулирования и задачи, которые оно призвано решить в рамках данного объекта. Объектом правового обеспечения начиональной безопасности, по мнению автора, является сфера национальной безопасности, а предметом - те отношения и деятельность в этой сфере, которые нуждаются в правовом обеспечении. Исходя из предложенного понимания объекта и предмета правового обеспечения, вычленяется предметная область названного правового обеспечения. Использованы общетеоретические методы научного анализа, необходимые для раскрытия темы статьи. На основе изучения современного состояния и теоретического осмысления правового обеспечения национальной безопасности делаются выводы об объекте, предмете и задачах этого обеспечения. Подчеркивается, что проблема объекта, предмета и задач правового обеспечения начиональной безопасности имеет не только чисто теоретический, но и сугубо практический характер. Определение предмета правового обеспечения начиональной безопасности позволило более четко сформулировать иель и основные задачи, стоящие перед данным обеспечением. Делается вывод о том, что сегодня с определенной долей условности можно говорить о том, что в России в основном создана законодательная основа обеспечения национальной безопасности. Вместе с тем современное состояние законодательной основы обеспечения национальной безопасности можно определить как состояние системы, находящейся в стадии формирования, а потому неизбежно несущей черты переходного этапа. Ключевые слова: национальная безопасность, правовое обеспечение безопасности, правовое регулирование безопасности, объект правового регулирования, предмет правового регулирования, задачи правового обеспечения, отношения национальной безопасности, безопасность соииальной системы, система наицональной безопасности, законодательная основа безопасности.
\end{abstract}

оставной частью обеспечения национальной безопасности является ее правовое обеспечение. Исходя из этимологии слова «обеспечивать», правовое обеспечение национальной безопасности можно определить как создание правовыми средствами необходимых условий для защищенности личности, общества и государства от внутренних и внешних угроз. Создание таких условий достигается с помощью правового регулирования отношений в сфере обеспечения национальной безопасности ${ }^{1}$.

Правовое обеспечение национальной безопасности требует четко определить тот объект, отношения

\footnotetext{
В научной литературе используется целый ряд понятий, характеризующих динамическое содержание права: действие права, правовое регулирование, правовое обеспечение, правовая охрана и другие. Объем и предмет рассмотрения статьи не позволяют в полной мере уделить внимание дискуссионным аспектам соотношения этих понятий, поэтому примем в качестве исходного положения тождественность понятий правового обеспечения и правового регулирования, хотя при более внимательном подходе между ними можно обнаружить различия.
}

в котором подлежат правовому регулированию, предмет этого регулирования и задачи, которые оно призвано решить в рамках данного предмета.

Под объектом правового регулирования в юридической литературе обычно понимается та сфера общественной жизни, область социального пространства, в которой действует право. Правильное определение сферы и пределов правового регулирования необходимо для того, чтобы исключить использование юридических инструментов в сферах взаимодействия людей, требующих иных средств социальной регуляции. По мнению В.И. Червонюка, эта сфера представляет совокупность неупорядоченных отношений и фактов, упорядочение которых объективно невозможно без использования правовых средств. Сфера правового регулирования есть область потенциальных правовых отношений ${ }^{2}$. Как можно понять из его рассуждений,

\footnotetext{
2 См.: Общая теория права и государства / под ред. В.В. Лазарева. М.: Норма, 2010. С. 151.
} 
он не разделяет объект и предмет правового регулирования, под которым понимает те разновидности общественных отношений, действий индивидов, коллективов людей, которые: а) объективно могут быть урегулированы правом; б) в данных условиях требуют юридического воздействия ${ }^{3}$.

Другие ученые придерживаются иной позиции. Они относят к объекту правового регулирования те общественные отношения, которые регулируются правом и вследствие этого становятся правовыми отношениями. При таком понимании предмет правового регулирования - это качественно однородный вид общественных отношений, которые регулируются соответствующей отраслью права ${ }^{4}$.

Следуя данной позиции, вопрос о том, являются ли отношения национальной безопасности самостоятельным предметом правового регулирования - дискуссионный, поскольку, во-первых, нуждается в обосновании однородность этих отношений и, во-вторых, очевидна их относимость к различным отраслям права.

Если исходить из того, что объект - это та сфера социальной действительности, на которую направлена деятельность субъекта, а предмет - та часть, сторона этой сферы, которая подлежит воздействию, можно,на наш взгляд, сделать вывод, что объектом правового обеспечения национальной безопасности является сфера национальной безопасности, а предметом - те отношения и деятельность в этой сфере, которые нуждаются в правовом обеспечении.

В современной научной литературе пока не сложилось единого понимания содержания национальной безопасности как объекта и предмета правового обеспечения. Так, А.Г. Залужный и В.В. Данилейко полагают, что объектом правового обеспечения национальной безопасности являются основные закономерности возникновения, формирования и развития отношений в указанной сфере, а также деятельность субъектов правового обеспечения национальной безопасности России по созданию четкого правового механизма выявления, устранения и нейтрализации угроз безопасности личности, общества и государства ${ }^{5}$. Соглашаясь с тем, что объектом

\footnotetext{
3 См.: Там же.

4 См., напр.: Головистикова А.Н., Дмитриев Ю.А. Проблемы теории государства и права. М.: Изд-во Эксмо, 2005. С. 492.

5 См.: Залужный А.Г., Данилейко В.В. Правовое регулирование в сфере национальной безопасности: теоретический аспект // Современное право. 2010. № 4. С. 71.
}

правового обеспечения национальной безопасности являются общественные отношения в указанной сфере, вместе с тем вызывает сомнение тезис об отнесении к такому объекту основных закономерностей возникновения, формирования и развития этих отношений. Закономерности в большей мере являются объектом научного познания, а не правового регулирования. Правовыми средствами можно создавать условия для проявления закономерностей, но нельзя отменить или запретить это проявление. Закономерности потому и являются таковыми, что они не зависят от воли и желаний людей. Как верно замечает В.В. Лазарев, «в предмет правового регулирования входят волевые отношения, что исключает распространение действия права на события или состояния, в которых не участвует человеческая воля. Повлиять на их ход человечество не может. Здесь оно бессильно» ${ }^{6}$.

Точно так же предметом правового обеспечения национальной безопасности не могут быть «имеющие значение для познавательной и предметнопрактической деятельности юридические нормы, законодательные и иные нормативные правовые акты, связанные с отношениями в рассматриваемой сфере, с деятельностью субъектов правового обеспечения национальной безопасности России» ${ }^{7}$, поскольку предмет правового регулирования отвечает на вопрос: что регулируется правом? Очевидно, что правом в лучшем случае может регулироваться процесс создания и реализации юридических норм, законодательных и иных нормативных правовых актов, но не сами нормы и акты.

Следует учитывать, что данная проблема имеет не только чисто теоретический, но и сугубо практический характер. В зависимости от того, какие именно отношения включаются в сферу национальной безопасности и, следовательно, составляют объект и предмет правового регулирования, могут по-разному решаться многие вопросы практического содержания, вырабатываться те или иные положения, выводы и рекомендации, касающиеся сферы национальной безопасности России и имеющие прикладное значение.

Очевидно, что отношения национальной безопасности - это не отношения, связанные с безопасностью той или иной нации в ее марксистском

\footnotetext{
6 Проблемы общей теории права и государства. Под общ.ред. В.С. Нерсесянца. М.: Изд. группа НОРМА-ИНФРА, 1999. С. 416.
}

7 Там же. 


\section{Национальная безопасность - № 2(31) • 2014}

понимании. И в Стратегии национальной безопасности Российской Федерации до 2020 года, и в ряде нормативных правовых актов понятие национальной безопасности употребляется в ином, более широком, не связанном с этническими признаками смысле ${ }^{8}$.

8 В нашей стране до начала 90-х годов XX в. термин «национальная безопасность» не получил распространения прежде всего в силу иного содержания, вкладываемого в понятия «нация», «национальное». Если в западных государствах доминирует принцип «одна нация - одна страна», то в России в общественном сознании прочно утвердилось марксистское понимание нации, национального как связанного с этносами. Введение в политический, а затем и в научный оборот заимствованного из западного лексикона термина «национальная безопасность» породило неоднозначное его понимание.

Так, нередко в понятии «национальная безопасность» акцент делается на слове «национальная», и в этом смысле оно толкуется как безопасность отдельной нации. Поэтому противники данного термина используют аргумент, что Россия - многонациональная страна и использование термина «национальная безопасность» есть не что иное, как проявление шовинизма, господства одной нации над другими. В этом аспекте национальная безопасность является составным элементом безопасности страны наряду с политической, экономической, социальной и другой безопасностью. Справедливости ради следует отметить, что вышеназванное понимание национальной безопасности в «чистом виде» в научных разработках употребляется достаточно редко. В попытках избежать обвинений в националистических тенденциях, связанных с подобным толкованием национальной безопасности, предлагаются новые термины, такие, например, как общенациональная безопасность.

Чаще всего, учитывая многонациональный состав России и закрепившееся в российском менталитете понимание национального, а также стремясь выйти на уровень безопасности России в целом, говорится о национально-государственной безопасности. Однако это еще больше запутывает вопрос, поскольку дает простор для не совсем корректных выводов, провоцирующих сепаратизм.

В этой связи некоторые исследователи предлагают вернуться к термину «государственная безопасность», заменив им термин «национальная безопасность» как не совсем корректный (см., напр.: Рогов А., Федотова Ю. Государственная безопасность: элемент или содержание национальной безопасности Российской Федерации // Власть. 2013. № 12.С. 131).

Все же большинство разделяют позицию американской и французской политологических школ, которые рассматривают нацию как согражданство, и потому в понятии «национальная безопасность» национальное понимается ими как относящееся к той или иной стране, независимо от проживающих в ней национальных образований.. В этом случае национальная безопасность отождествляется с безопасностью государственно-организованного общества во всех ее проявлениях и видах. Именно так понимается национальная безопасность в Стратегии национальной безопасности Российской Федерации до 2020 года.

В конечном счете, вопрос не в терминах, а в том содержании, которое за ним скрывается. На наш взгляд, за последние два
Не менее существенным в национальной безопасности для определения круга общественных отношений, попадающих в сферу правового регулирования, является характеристика самой безопасности. В большинстве определений безопасность трактуется с точки зрения охранительной парадигмы как состояние защищенности от угроз, опасностей. Эта позиция закреплена и в Стратегии национальной безопасности Российской Федерации до 2020 года, и во многих научных разработках. В принципе такой подход логичен, хотя и предоставляет возможность для критики. Сама этимология слова «безопасность» предполагает противодействие опасности, защищенность от нее. Вместе с тем, на наш взгляд, не всякое явление, угрожающее тому или иному социальному субъекту, представляет для него опасность. Так, вряд ли можно считать опасностью любое воздействие, вызывающее изменение этого субъекта. В таком случае безопасность социальной системы будет означать защищенность от внутренних и внешних воздействий на нее с целью изменения. Очевидно, что такое понимание безопасности фактически является тормозом развития и в конечном счете приводит к разрушению системы.

Безопасной, с нашей точки зрения, является та социальная система, которая обладает возможностью самосохранения на основе развития. Данное положение не означает, что системе не угрожают опасности. Напротив, только при наличии опасностей система может развиваться. Речь идет о том, что опасностью для социальной системы является лишь то, что сдерживает или прекращает ее развитие. Не случайно в Стратегии национальной безопасности Российской Федерации до 2020 года особый акцент в определении безопасности делается на устойчивости развития 9 .

К сожалению, нормативно закрепленного определения национальной безопасности на уровне федерального закона пока не имеется. Символично, что даже в профильном федеральном законе «О безопасности ${ }^{10}$ законодатель уклонился от такого

десятилетия термин «национальная безопасность» в последнем понимании стал таким же общеупотребительным, как, скажем, национальный доход или национальное богатство, и вряд ли имеет смысл изобретать что-то новое.

9 См.: Указ Президента РФ от 12.05.2009 № 537 «О Стратегии национальной безопасности Российской Федерации до 2020 года» // «Российская газета». 2009. 19 мая.

10 См.: Федеральный закон от 28.12.2010 № 390-Ф3 «О безопасности» // Российская газета. 2010. 29 декабря. 
определения, полагая, видимо, что оно уже имеется в Стратегии национальной безопасности. Тем не менее, анализ нормативной правовой базы позволяет вычленить основные характеристики национальной безопасности, которые очерчивают круг отношений, требующих правового регулирования. К ним следует отнести отношения, обеспечивающие:

- конституционные права и свободы, качество и уровень жизни граждан;

- суверенитет, территориальную целостность и устойчивое развитие Российской Федерации;

- оборону страны;

- безопасность государства.

Соответственно, обеспечение национальной безопасности представляет собой систематическую деятельность государственных органов, общественных институтов и отдельных граждан, направленную на защиту личности, общества и государства от внутренних и внешних угроз.

Таким образом, с нашей точки зрения, в качестве предмета правового обеспечения следует признать отношения в сфере национальной безопасности, выражающие состояние защищенности личности, общества и государства от внутренних и внешних угроз, которое позволяет обеспечить конституционные права, свободы, достойные качество и уровень жизни граждан, суверенитет, территориальную целостность и устойчивое развитие Российской Федерации, оборону и безопасность государства.

Определение предмета правового обеспечения национальной безопасности позволяет более четко сформулировать цель и основные задачи, стоящие перед данным обеспечением. Общей целью правового обеспечения национальной безопасности следует признать упорядочение, урегулирование и охрану общественных отношений, способствующих безопасному существованию и развитию личности, общества и государства.

Среди задач такого правового обеспечения особое внимание следует обратить на те, которые в наибольшей степени раскрывают его содержание. К их числу следует отнести:

- определение угроз безопасности личности, общества и государства;

- закрепление на законодательном уровне национальных интересов;

- определение основных направлений обеспечения национальной безопасности в различных сферах жизни общества;
- создание организационных основ системы обеспечения национальной безопасности (определение основных задач, принципов организации, внутренней структуры, сил и средств, места в механизме государства, закрепление функций и разграничение полномочий органов государства, входящих в систему обеспечения национальной безопасности);

- обеспечение баланса интересов личности, общества и государства в сфере обеспечения национальной безопасности;

- установление и реализация юридической ответственности за противоправные деяния, посягающие на безопасность личности, общества и государства;

- $\quad$ формирование системы предупреждения правонарушений в сфере национальной безопасности;

- правовое воспитание и формирование правосознания граждан и должностных лиц, ориентированные на обеспечение национальной безопасности.

Сегодня с определенной долей условности можно говорить о том, что в России в основном создана законодательная основа обеспечения национальной безопасности, которая включает совокупность взаимосвязанных и внутренне согласованных основополагающих нормативных правовых актов, содержащих юридические принципы и нормы, направленные на правовое регулирование общественных отношений в сфере обеспечения национальной безопасности страны.

Вместе с тем правовая база регулирования отношений в этой сфере еще далека от совершенства, что связано с формированием новой структуры экономических, политических, социальных и духовных реалий как внутри страны, так и на международной арене. Специалисты отмечают, что в российском законодательстве не отражены реальные и действенные правовые механизмы адекватного противодействия новым угрозам безопасности Российской Федерации. Требуют уточнения и классификации сферы деятельности государства по обеспечению национальной безопасности. Противоречия, двойное толкование и декларативность положений соответствующих законов препятствуют их эффективному и целенаправленному исполнению.

Современное состояние законодательной основы обеспечения национальной безопасности можно определить как состояние системы, находящейся в стадии формирования, а потому неизбежно несущей черты переходного этапа. В этих условиях перед за- 


\section{Национальная безопасность - № 2(31) 2014}

конодателем стоит сложнейшая задача сформировать гибкую правовую систему, которая могла бы адекватно реагировать на происходящие экономические и социально-политические изменения в стране и за рубежом и вместе с тем обеспечить необходимый уровень национальной безопасности.

Первое, с чем сталкивается законодатель, - это отсутствие концепции развития нормативной правовой основы организации и функционирования системы обеспечения национальной безопасности России. Отсюда возникает множество вопросов, нуждающихся в качественном правовом решении. К их числу прежде всего относятся недостаточная системность в нормативном правовом регулировании, разобщенность субъектов обеспечения национальной безопасности, неоправданное дублирование их отдельных функций, недостаточный уровень взаимодействия и координации их деятельности.

Совершенствование правового регулирования обеспечения национальной безопасности с учетом этих обстоятельств позволит устранить имеющиеся в российском законодательстве пробелы и создать четкий механизм по выявлению, устранению и нейтрализации угроз безопасности личности, общества и государства. Фактически речь идет о формировании новой отрасли законодательства - законодательства в области обеспечения национальной безопасности ${ }^{11}$.

В этих условиях требуются новые подходы к определению стратегии правового обеспечения национальной безопасности, придание этому обеспечению системности и полноты. Существенную роль в решении этих проблем могут сыграть Стратегия национальной безопасности РФ до 2020 года, Доктрина информационной безопасности РФ, Военная доктрина РФ и ряд других политико-правовых документов. Большое значение в определении стратегии правового обеспечения национальной безопасности России имели результаты обсуждения проблем государственной, общественной, информационной, военной безопасности на заседаниях комитетов Совета Федерации и Государственной Думы, Совета Безопасности Российской Федерации. Значительный вклад в разработку концептуальных и правовых проблем обеспечения национальной безопасности России вносят ученые многих ведомств.

Однако, несмотря на столь пристальное внимание к данным проблемам и несомненные достижения в этой области, практика свидетельствует о необходимости проведения масштабных и долговременных научных исследований с целью создания целостной системы правового обеспечения в сфере национальной безопасности России. При этом важно, чтобы, вопервых, теория и практика тесно взаимодействовали и, во-вторых, в этой работе принимали участие представители не только силовых структур, но и гражданского общества, поскольку обеспечение национальной безопасности затрагивает интересы всех и каждого, является жизненно важной потребностью всей страны.

\section{Библиография}

1. Азизов РФ. оглы, Борченко В.А. Объект и предмет правового регулирования: проблема соотношения понятий // История государства и права. 2006. № 11.

2. Александров Р.А. О современном состоянии законодательства Российской Федерации в области национальной безопасности // Российский следователь. 2006. № 4.

3. Артамонова Я.С. Понятие «безопасность» на научно-теоретическом и правовом уровнях // Национальная безопасность / nota bene. 2011. №

4. Головистикова А.Н., Дмитриев Ю.А. Проблемы теории государства и права. М.: Изд-во Эксмо, 2005.

5. Гуськов Ю., Резник Е. Безопасность: проблемы постижения сущности // Власть. 2013. № 11.

6. Залужный А.Г., Данилейко В.В. Правовое регулирование в сфере национальной безопасности: теоретический аспект // Современное право. 2010. № 4.

7. Киреева Н.В. О системном подходе к определению основных категорий общей теории безопасности // Национальная безопасность / nota bene. 2013. № 6 .

8. Национальная безопасность: политико-правовые вопросы. Научное исследование / под общ. ред. М.П. Фомиченко. М.: РПА Минюста РФ, 2008.

\footnotetext{
11 См.: Правовая основа обеспечения национальной безопасности Российской Федерации / под ред. А.В. Опалева. М.: ЮНИТИ-ДАНА, 2004. С. 9.
} 
9. Общая теория права и государства / под ред. В.В. Лазарева. М.: Норма, 2010.

10. Правовая основа обеспечения национальной безопасности Российской Федерации / под ред. А.В. Опалева. М.: ЮНИТИ-ДАНА, 2004.

11. Проблемы общей теории права и государства / под общ. ред. В.С. Нерсесянца. М.: Изд. группа НОРМАИНФРА, 1999.

12. Рогов А., Федотова Ю. Государственная безопасность: элемент или содержание национальной безопасности Российской Федерации // Власть. 2013. № 12.

13. Урсул А.Д. Обеспечение национальной безопасности через приоритеты устойчивого развития // NB: Национальная безопасность. - 2013. - 1. - C. 1-61. DOI: 10.7256/2306-0417.2013.1.325. URL: http:// www.e-notabene.ru/nb/article_325.html

14. Андреев М.В. Конституционные и международные политико-правовые принципы обеспечения национальной безопасности // Право и политика. - 2013. - 6. - C. 803-808. DOI: 10.7256/18119018.2013.6.6446.

15. Урсул А.Д. Обеспечение национальной безопасности через приоритеты устойчивого развития // NB: Национальная безопасность. - 2013. - 1. - C. 1-61. DOI: 10.7256/2306-0417.2013.1.325. URL: http:// www.e-notabene.ru/nb/article_325.html/

16. Киреева Н.. О системном подходе к определению основных категорий общей теории безопасности. // Национальная безопасность / nota bene. — 2013. — № 6. — C. 11-26. DOI: .10.7256/2073-8560.2013.6.10240.

17. Е.О. Иванов. Понятие стратегического политического планирования. // Тренды и управление. — 2013. № 2. - C. 196-206. DOI: .10.7256/2307-9118.2013.2.5215.

18. А.Ю. Бельянинов. Безопасность России на Евразийском пространстве. // Национальная безопасность / nota bene. - 2013. — № 2. - C. 318-324. DOI: .10.7256/2073-8560.2013.02.10.

19. В.Л. Шульц. Сценарный анализ в управлении социальной безопасностью. // Национальная безопасность / nota bene. - 2012. - № 6. - C. 4-21. О. В. Остроухов. Политический риск в аспекте национальной безопасности (основы оптимизации политического риска). // Национальная безопасность / nota bene. 2012. - № 2. - С. 30-38.

20. Г. Г. Газимагомедов, Л. В. Давыдов. Конфликтные основания политической безопасности в современной России. // Национальная безопасность / nota bene. - 2012. - № 2. - C. 9-21.

21. Е.Б. Ганюшкина. Формирование международного экономического порядка. // Международное право и международные организации / International Law and International Organizations. - 2012. — № 1. C. $10-33$.

22. Я.С. Артамонова. Понятие «безопасность» на научно-теоретическом и правовом уровнях. // Национальная безопасность / nota bene. - 2011. — № 6. - С. 152-160.

23. А.К. Сковиков. Формирование институтов гражданского общества как важного фактора национальной безопасности Украины. // Национальная безопасность / nota bene. - 2012. - № 1. - С. 35-45.

\section{References}

1. Azizov RF. ogly, Borchenko V.A. Ob"ekt i predmet pravovogo regulirovaniya: problema sootnosheniya ponyatii // Istoriya gosudarstva i prava. 2006. № 11.

2. Aleksandrov R.A. O sovremennom sostoyanii zakonodatel'stva Rossiiskoi Federatsii v oblasti natsional'noi bezopasnosti // Rossiiskii sledovatel'. 2006. № 4.

3. Artamonova Ya.S. Ponyatie «bezopasnost'» na nauchno-teoreticheskom i pravovom urovnyakh // Natsional'naya bezopasnost' / nota bene. 2011. №

4. Golovistikova A.N., Dmitriev Yu.A. Problemy teorii gosudarstva i prava. M.: Izd-vo Eksmo, 2005.

5. Gus'kov Yu., Reznik E. Bezopasnost': problemy postizheniya sushchnosti // Vlast'. 2013. № 11.

6. Zaluzhnyi A.G., Danileiko V.V. Pravovoe regulirovanie v sfere natsional'noi bezopasnosti: teoreticheskii aspekt // Sovremennoe pravo. 2010. № 4.

7. Kireeva N.V. O sistemnom podkhode k opredeleniyu osnovnykh kategorii obshchei teorii bezopasnosti // Natsional'naya bezopasnost' / nota bene. 2013. № 6 . 


\section{Национальная безопасность - № 2(31) • 2014}

8. Natsional'naya bezopasnost': politiko-pravovye voprosy. Nauchnoe issledovanie / pod obshch. red. M.P. Fomichenko. M.: RPA Minyusta RF, 2008.

9. Obshchaya teoriya prava i gosudarstva / pod red. V.V. Lazareva. M.: Norma, 2010.

10. Pravovaya osnova obespecheniya natsional'noi bezopasnosti Rossiiskoi Federatsii / pod red. A.V. Opaleva. M.: YuNITI-DANA, 2004.

11. Problemy obshchei teorii prava i gosudarstva / pod obshch. red. V.S. Nersesyantsa. M.: Izd. gruppa NORMAINFRA, 1999.

12. Rogov A., Fedotova Yu. Gosudarstvennaya bezopasnost': element ili soderzhanie natsional'noi bezopasnosti Rossiiskoi Federatsii // Vlast'. 2013. № 12.

13. Ursul A.D. Obespechenie natsional'noi bezopasnosti cherez prioritety ustoichivogo razvitiya // NB: Natsional'naya bezopasnost'. - 2013. - 1. — C. 1-61. DOI: 10.7256/2306-0417.2013.1.325. URL: http://www.e-notabene.ru/ nb/article 325.html

14. Andreev M.V. Konstitutsionnye i mezhdunarodnye politiko-pravovye printsipy obespecheniya natsional'noi bezopasnosti // Pravo i politika. — 2013. - 6. - C. 803-808. DOI: 10.7256/1811-9018.2013.6.6446.

15. Ursul A.D. Obespechenie natsional'noi bezopasnosti cherez prioritety ustoichivogo razvitiya // NB: Natsional'naya bezopasnost'. - 2013. - 1. - C. 1-61. DOI: 10.7256/2306-0417.2013.1.325. URL: http://www.e-notabene.ru/ $\mathrm{nb} /$ article $325 . \mathrm{html} /$

16. Kireeva N.. O sistemnom podkhode k opredeleniyu osnovnykh kategorii obshchei teorii bezopasnosti. // Natsional'naya bezopasnost' / nota bene. — 2013. — № 6. — C. 11-26. DOI: .10.7256/2073-8560.2013.6.10240.

17. E.O. Ivanov. Ponyatie strategicheskogo politicheskogo planirovaniya. // Trendy i upravlenie. — 2013. — № 2. C. 196-206. DOI: .10.7256/2307-9118.2013.2.5215.

18. A.Yu. Bel'yaninov. Bezopasnost' Rossii na Evraziiskom prostranstve. // Natsional'naya bezopasnost' / nota bene. 2013. — № 2. — C. 318-324. DOI: .10.7256/2073-8560.2013.02.10.

19. V.L. Shul'ts. Stsenarnyi analiz v upravlenii sotsial'noi bezopasnost'yu. // Natsional'naya bezopasnost' / nota bene. 2012. - № 6. - C. 4-21. O. V. Ostroukhov. Politicheskii risk v aspekte natsional'noi bezopasnosti (osnovy optimizatsii politicheskogo riska). // Natsional'naya bezopasnost' / nota bene. — 2012. — № 2. — C. 30-38.

20. G. G. Gazimagomedov, L. V. Davydov. Konfliktnye osnovaniya politicheskoi bezopasnosti v sovremennoi Rossii. // Natsional'naya bezopasnost' / nota bene. — 2012. — № 2. - C. 9-21.

21. E.B. Ganyushkina. Formirovanie mezhdunarodnogo ekonomicheskogo poryadka. // Mezhdunarodnoe pravo i mezhdunarodnye organizatsii / International Law and International Organizations. — 2012. — № 1. — C. 10-33.

22. Ya. S. Artamonova. Ponyatie «bezopasnost'» na nauchno-teoreticheskom i pravovom urovnyakh. // Natsional'naya bezopasnost' / nota bene. - 2011. — № 6. - C. 152-160.

23. A. K. Skovikov. Formirovanie institutov grazhdanskogo obshchestva kak vazhnogo faktora natsional'noi bezopasnosti Ukrainy. // Natsional'naya bezopasnost' / nota bene. — 2012. — № 1. - C. 35-45. 